\title{
Channelized and hillslope sediment transport and the geomorphology of mountain belts
}

\author{
Heinz Schneider - Marco Schwab - Fritz Schlunegger
}

Published online: 3 April 2008

(C) Springer-Verlag 2008

Erratum to: Int J Earth Sci (Geol Rundsch) (2008)

\section{7:179-192}

DOI 10.1007/s00531-006-0164-9

Unfortunately, in the printed version of this article the presentation of the following figures was incorrectly given in black and white:

Figure 3 page 184

Figure 4 page 185

Figure 6 page 186

Figure 8 page 188

Please find below these figures in colour together with their respective caption.

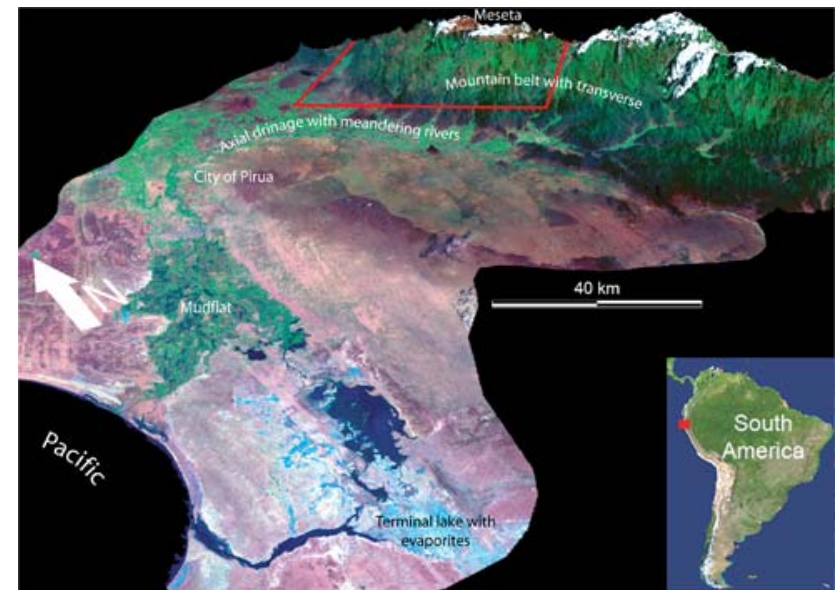

Fig. 3 Three-dimensional overview of the Piura drainage basin, northern Peru. Landsat ETM+7, US Geological Survey (1993-2000). The red lines mark the limit of Fig. 4. Elevation model, US Geological Survey (2006). Source for this dataset was the Global Land Cover Facility

The online version of the original article can be found under doi:10.1007/s00531-006-0164-9.

H. Schneider $(\bowtie) \cdot$ M. Schwab · F. Schlunegger Institute of Geological Sciences, University of Bern,

Baltzerstrasse 1, 3012 Bern, Switzerland

e-mail: Schneider@geo.unibe.ch

F. Schlunegger

e-mail: fritz.schlunegger@geo.unibe.ch 
Fig. 4 ASTER mosaic-scene of the Andes of northern Peru (a). The Meseta is located at an elevation of ca. $3,600 \mathrm{~m}$ above sea level. Small arrows show the location and direction of photos in Fig. 5. Note the difference in morphometry between the western and eastern drainages
Fig. 6 Pattern of topographic slopes in the Andes of northern Peru. Projection, UTM Z17S WGS84
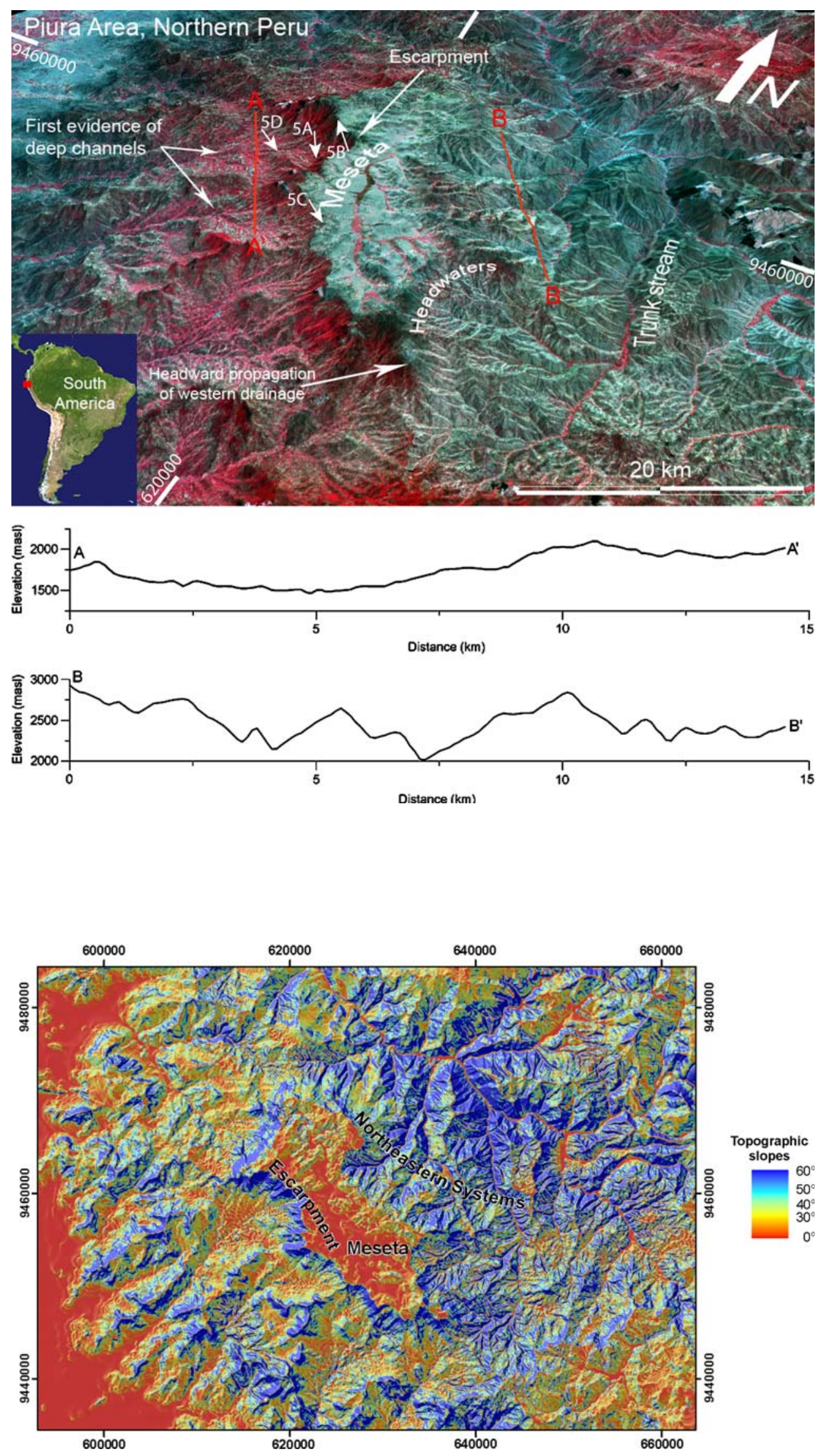
Fig. 8 Pattern of topographic slopes in the eastern Swiss Alps. Projection, CH1903 LV03

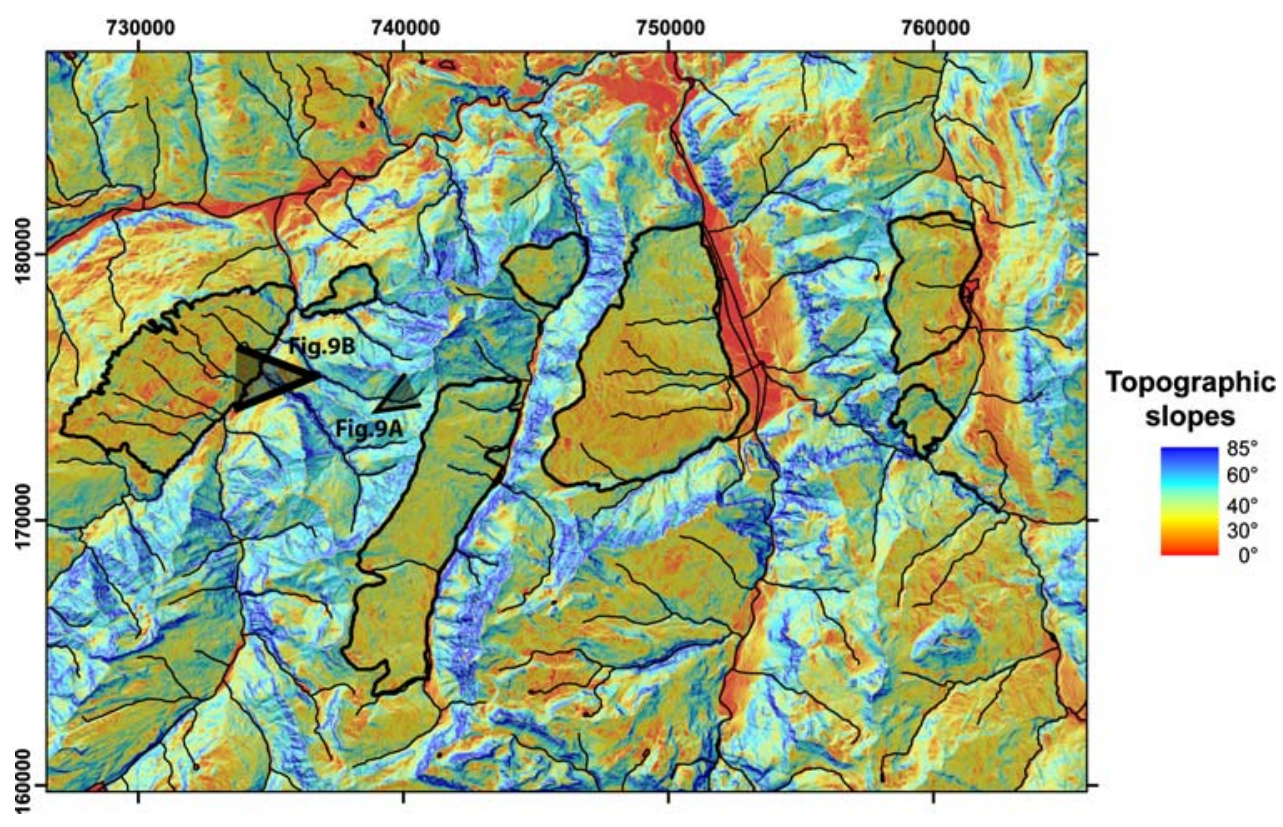

